\title{
Wind Tunnel Testing of a Small Wind Turbine Darrieus-H, With Asymmetric Airfoil, For Auto Start
}

\author{
Jorge Lassig ${ }^{1}$, Juan Valle Sosa ${ }^{2}$, Ubaldo Jara ${ }^{3}$ \\ ${ }^{12} 3$ (Department of Mechanical Eng., Faculty of Engineering, Universidad Nacional del Comahue, Neuquén, \\ Argentina)
}

\begin{abstract}
The Darrieus model was invented by a French engineer named George Jeans Maria Darrieus. He presented his patent in 1931 in the US [1] which included curved and constant section blades, now called Darrieus-H or Giromill. Its boom was won between the 1970s and 1980s, and then was dismissed for various reasons, compared with horizontal axis turbines [2].In particular, vertical axis wind turbines Darrieus type today are being considered as one of the most attractive solutions to be installed on roofs of buildings (auto sustainable buildings), due to its low visual impact, reduced noise emissions and better response to a turbulent flow [3].A difficulty of the Darrieus type wind turbines is that it lacks self starter. This is partly because in the past have been used only symmetrical airfoils, such as the NACA 4-digit number, for exampled NACA 0012, 0015, 0018. This inability auto start was a technical disadvantage for this type of wind turbine. In recent years it has begun experimenting with airfoils not symmetrical and it has been determined that in some cases they allow the booting [4].In this paper the results of a series of tests with a small turbine Darrieus-H four blades are presented, with a non-symmetrical profile of the $S$ series, which was tested in a wind tunnel, varying the pitch of the blade, to find the wind speed auto start, which was $4 \mathrm{~m} / \mathrm{s}$
\end{abstract}

Keywords: Darrieus-H, Testing, Wind Tunnel.

\section{Introduction}

The Darrieus model was invented by a French engineer named George Jeans Maria Darrieus. He presented his patent in 1931 in the US [1] which included curved and constant section blades. The Darrieus type VAWTs are basically driven by the lifting force. The turbine has two or more blades with airfoil shaped that are attached to a vertical axis of rotation. The wind flows over the contours of the airfoil of the blade and creates aerodynamic lift, which drives them.A variation of the original Darrieus turbine was developed in National Research Council of Canada [5, 6]. It is called Darrieus Troposkien, which achieves to minimize the bending stress on the blades, because of their shape follow the deformation caused by centrifugal force and weight. In the market for small-scale wind turbines, the Darrieus straight blade, they are called Giromill or Darrieus-H is currently the most attractive being its simplest design. The Giromill or Rotors- $\mathrm{H}$, as shown in Figure $1 \mathrm{~b}$ have been developed in the UK by research conducted during the 1970s and 1980s.

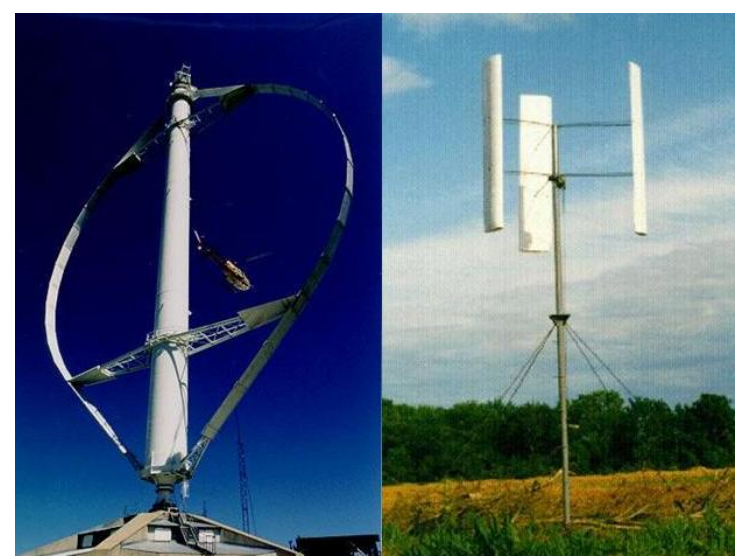

Figure 1: (a) Conventional Darrieus - (b) Darrieus-H or Giromill.

It was found that the effect created behind a blade limit the speed of the relative wind of the opposite blade, and this could drive the entire configuration of the blade forward, therefore, rotor- $\mathrm{H}$ could become apparatus capable of achieve self-starting and self-regulation in all wind speeds.These settings are divided into two categories: fixed pitch and variable pitch. It has been found that fixed pitch VAWTs provide a pair incorrect start [7]. 
By contrast settings in modern VAWT blade variable pitch, they have managed to overcome the problem of torque, but they are too complicated, which makes it impractical for low power applications $[X X]$.Most research activities carried out previously in the VAWT focused on straight blades equipped with lift surfaces symmetrical support (such as NACA series 4-digit 0012, 0015, 0018), which were not able to achieve self-starter This inability to self-starter in the past was due to several factors (technical factors, inadequate research and funding), but the most dominant are due to aerodynamic factors In recent years it has begun experimenting with airfoils not symmetrical and it has been determined that in some cases they allow the selfstarter, although the auto start more accurate is obtained by having pitch variation on the blades. On the other hand, if an internet survey is done, can see that there are a handful of commercial products VAWTs straight blades, but there is no reliable information from an independent source, regarding the performance of these products and the claims made by manufacturers have not yet verified with authenticity.In the market for smallscale wind turbines, the Darrieus-H seems more profitable than conventional Darrieus.

\section{Math Expressions For Analysis Aerodynamic Blades Type Darrieus}

The blades of the Darrieus in its aerodynamic analysis is quite complex. The general mathematical expressions, which are common to most aerodynamic models used in the design of wind turbines type VAWT, are shown below.

\subsection{The variation of the local angle of attack.}

Flow rates on the sides upstream and downstream of the Darrieus type VAWTs are not constant, as shown in Figure 2The figure shows that the flow is considered in the axial direction. The tangential velocity component $\mathrm{Vt}$ and the normal velocity component $\mathrm{Vn}$ are obtained from the following expressions:

$$
\begin{aligned}
& \mathrm{V}_{\mathrm{t}}=\mathrm{R} \cdot \omega+\mathrm{V}_{\mathrm{a}} \cdot \operatorname{Cos} \theta \\
& \mathrm{V}_{\mathrm{n}}=\mathrm{V}_{\mathrm{a}} \cdot \operatorname{Sin} \theta
\end{aligned}
$$

Where $\mathrm{Va}$ is the axial flow rate (the induced velocity) through the rotor, $\omega$ is the rotational speed, $\mathrm{R}$ is the radius of the turbine, and $\theta$ is the azimuth angle. Referring to Figure 2, the angle of attack $(\alpha)$ can be expressed as:

$$
\alpha=\tan ^{-1}\left(\mathrm{~V}_{\mathrm{n}} / \mathrm{V}_{\mathrm{c}}\right)
$$

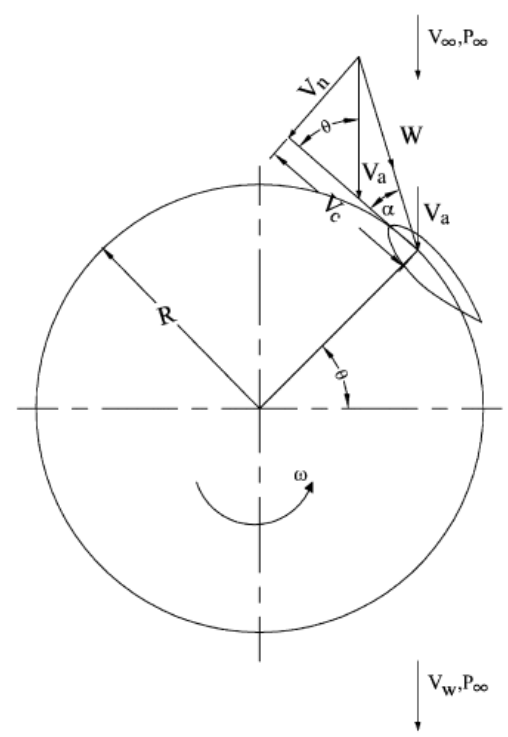

Figure 2: Diagram of decomposition speeds acting on a blade element in a Darrieus turbine- $\mathrm{H}$.

Substituting the values of $\mathrm{Vt}$ and $\mathrm{Vn}$ and dimensionless, becomes:

$$
\alpha=\tan ^{-1}\left[\frac{\operatorname{Seno} \theta}{\left(R \omega / V_{\infty}\right) /\left(V_{a} / V_{\infty}\right)+\operatorname{Cos} \theta}\right]
$$

$\mathrm{V} \infty$ where is the wind speed in the free stream. If we consider the pitch of the blade,

$$
\alpha=\tan ^{-1}\left[\frac{\operatorname{Seno} \theta}{\left(R \omega / V_{\infty}\right) /\left(V_{a} / V_{\infty}\right)+\operatorname{Cos} \theta}\right]-\gamma
$$

Where $\gamma$ is the angle of the blades. 


\subsection{Variation of the relative velocity of local flow.}

The relative flow rate $(\mathrm{W})$ can be obtained as (see figure 2):

$$
W=\sqrt{V_{t}^{2}+V_{n}^{2}}
$$

Replacing the values of $\mathrm{Vt}$ and $\mathrm{Vn}$ (Equations 1 and 2) in equation (6), and reducing the dimensions, you can be found as the velocity ratio:

$$
\frac{W}{V_{\infty}}=\frac{W}{V_{a}} \cdot \frac{V_{a}}{V_{\infty}}=\frac{V_{a}}{V_{\infty}} \sqrt{\left[\left(\frac{R \omega}{V_{\infty}} / \frac{V_{a u}}{V_{\infty}}\right)+\operatorname{Cos} \theta\right]^{2}+\operatorname{Seno}^{2} \theta}
$$

\subsection{Variation of tangential and normal forces}

The directions of the forces lift and drag, and their normal and tangential components, are indicated in Figure 3.

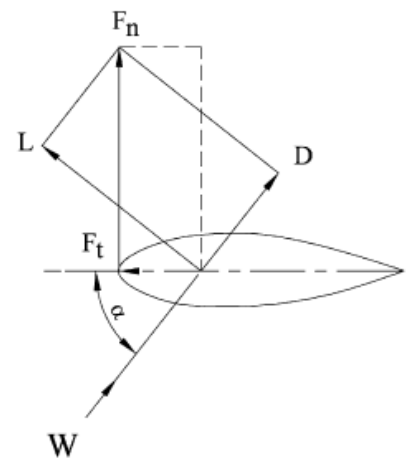

Figure 3: Diagram of decomposition of forces acting on a blade element in a Darrieus turbine-H.

The tangential force coefficient $(\mathrm{Ct})$ is basically the difference between the tangential components of the forces of lift and drag. Similarly, the normal force coefficient $(\mathrm{Cn})$ is the difference between normal and supporting components drag forces. Expressions of $\mathrm{Ct}$ and $\mathrm{Cn}$ can be written as:

$$
\begin{aligned}
& \mathrm{C}_{\mathrm{t}}=\mathrm{C}_{\mathrm{l}} \cdot \operatorname{Sin} \alpha-\mathrm{C}_{\mathrm{d}} \cdot \operatorname{Cos} \alpha \\
& \mathrm{C}_{\mathrm{n}}=\mathrm{C}_{\mathrm{l}} \cdot \operatorname{Cos} \alpha+\mathrm{C}_{\mathrm{d}} \cdot \operatorname{Sin} \alpha
\end{aligned}
$$

Tangential and normal net forces can be defined as:

$$
\begin{aligned}
& \mathrm{F}_{\mathrm{t}}=\mathrm{C}_{\mathrm{t}} 1 / 2 \rho \mathrm{CH} \mathrm{W}^{2} \\
& \mathrm{~F}_{\mathrm{n}}=\mathrm{C}_{\mathrm{n}} 1 / 2 \rho \mathrm{CH} \mathrm{W}^{2}
\end{aligned}
$$

Where $\rho$ is the air density, which is the blade chord and $\mathrm{H}$ is the height of the turbine.

\section{Aerodynamic Airfoils Low Reynolds}

When you are working with conventional profiles at low Reynolds numbers, one of the problems that appear is laminar separation without re early adhesion. A shear layers are separated is called the "bubble laminar separation" (Horton 1968 [8]), as shown in Figure 4. This shear layer reduces $C_{L}$ and $C_{D}$ increases, and ends with the complete flow separation and stall airfoil. According to the type of separation are generated so-called short or long bubbles, depending on the incident flow and geometric characteristics of the airfoil.

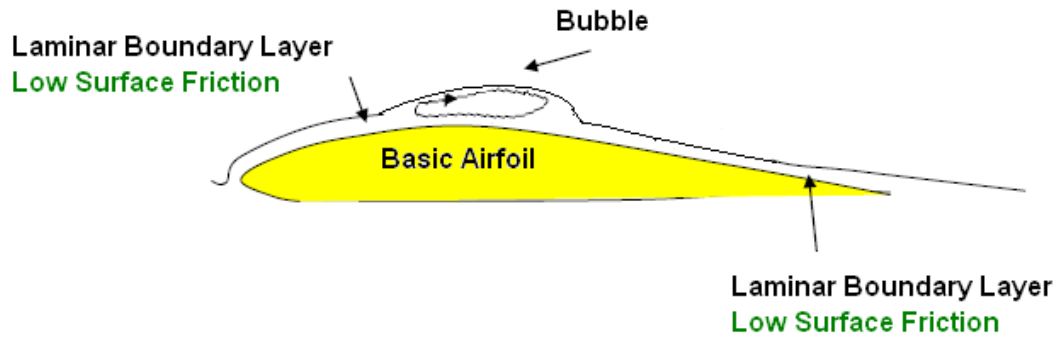

Figure 4: for low Reynolds numbers, the flow remains laminar and the bubble can be adhered modifying the performances airfoil. 
To avoid or delay this phenomenon, airfoils for low Reynolds ([9], [10], [11], [12]) were developed, whose main characteristic is that they present a gradual evolution of pressure on the upper surface, without abrupt jump, in the range of Reynolds from 50,000 to 500,000 thereby obtaining adequate lift distribution. These airfoils are used in the design of aircraft, including gliders competition, radio controlled aircraft (drones), and modern wind turbines.

\section{1.- Airfoil Wind Power by Control Aerodynamic Stall}

When the aerospace industry entered the market manufacture of wind turbines by the late 1970', he developed the power control by means of a suitable aerodynamic design in which the angle of nominal attack profile did not take the higher fineness; on the contrary it was located near the stall. When the aerospace industry entered the market manufacture of wind turbines by the late 1970', he developed the power control by means of a suitable aerodynamic design in which the angle of nominal attack airfoil did not take the higher lift -to-drag ratio, however it was located near the stall.

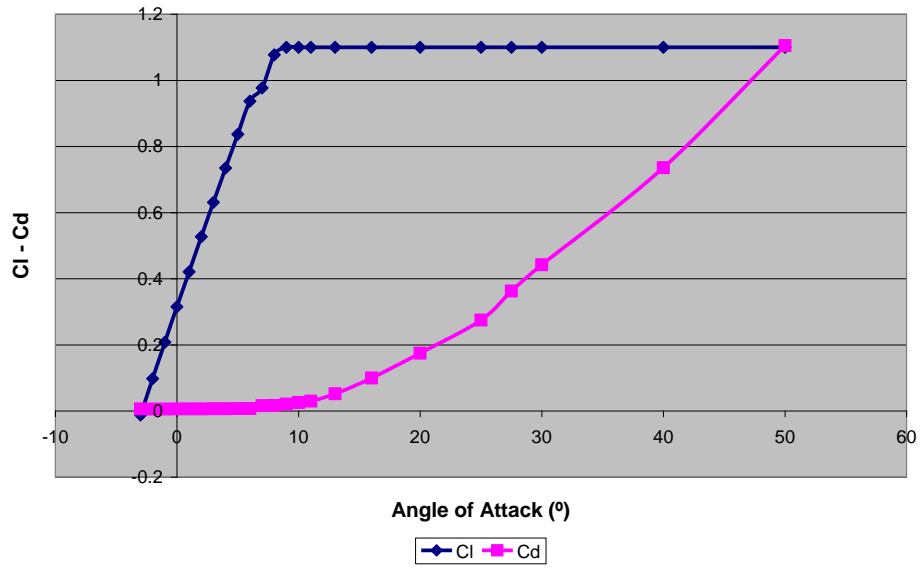

Figure 6: aerodynamic airfoil characteristics S813.

Airfoils classic NACA had a $\mathrm{Cl}$ curve vs. $\alpha$ with fast inputs in stall, so they began to study variants they managed to spread in tens of degrees stall and were born a series of airfoils at high angles of attack kept constant support without stalling, and increased drag, gaining control search. An example of this is the airfoil Somers S813 [13], where in Figure 6 are plotted the curves of the coefficient of lift and drag, it is seen that from a low angle of attack the lift remains constant until 50th, while the drag is considerably increased with the angle of attack.

\subsection{Wind Tunnel Test Airfoil S813}

To verify the characteristics of the extent of stall airfoil S813, a small wing was constructed with the dimensions given in Table I, where the elongation is practically 1.

\begin{tabular}{|l|l|l|}
\hline Airfoil & Chord & Span \\
\hline S813 & $16 \mathrm{~cm}$ & $15,1 \mathrm{~cm}$ \\
\hline
\end{tabular}

Table I: size of the small wing tested in wind tunnel.

The wind tunnel No. 1 FI-UNCo was used, the test section has an area of $0.09 \mathrm{~m} 2$, is open type, uniform profile, and turbulence intensity of 5\%. The speed was measured with a hot wire anemometer TSI Incorporated Model 8330-M, and lift a piezometric balance. The test was conducted at a speed of $10 \mathrm{~m} / \mathrm{s}$, so the Reynolds number was $1,06 \times 10^{5}$. The images of Figure 7 show the shape and positioning inside the wind tunnel of the small wing.

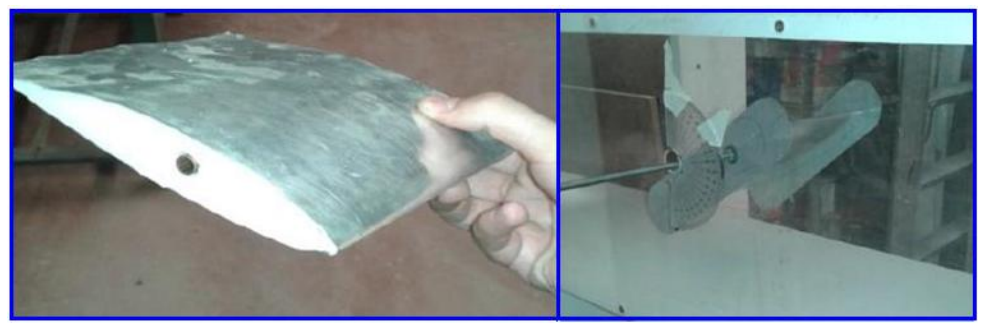

Figure 7: small wing built on an airfoil S813, and wind tunnel testing. 
The results are shown in the graph of Figure 8, and when compared with the airfoil (wing infinite aspect ratio), shows that the extension properties of the lift are maintained.

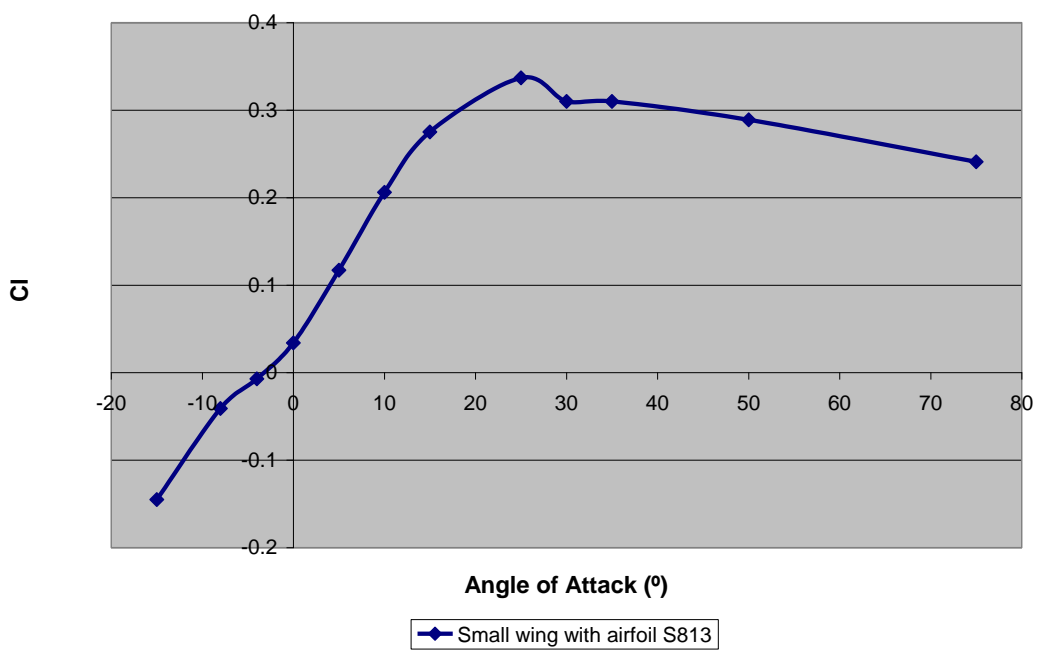

Figure 8: Variation coefficient of lift of the small wing, as a result of wind tunnel testing.

\section{3.- Airfoils high versus low Reynolds numbers}

From the data of $\mathrm{Cl}$ and $\mathrm{Cd}$ of S813 and NACA 0009 airfoils, and using equation (9) the coefficient of tangential thrust of a blade Darrieus-H was calculated and the graph in Figure 9.It can be seen in this figure that the symmetrical airfoil for high angles of attack produces a negative tangential force (it opposes the rotation of the turbine), on the other hand the S813 airfoil continues to generate positive tangential force at high angles of attack, thus enabling standing still, and if the wind is incident on a blade at high angles of attack, this produces a torque that can set in motion the wind turbine. It is the problem of not having auto start symmetric airfoils, and possessing self starter for certain non-symmetrical airfoils. Figure 9 is inferred that this airfoil, with low Reynolds numbers, the auto start is possible. The power generated depends on the dimensions of the rotor and blade angle, which will require proper dimensioning. The profile S813, besides allowing the auto start-up, also functions as power control entry into stall.

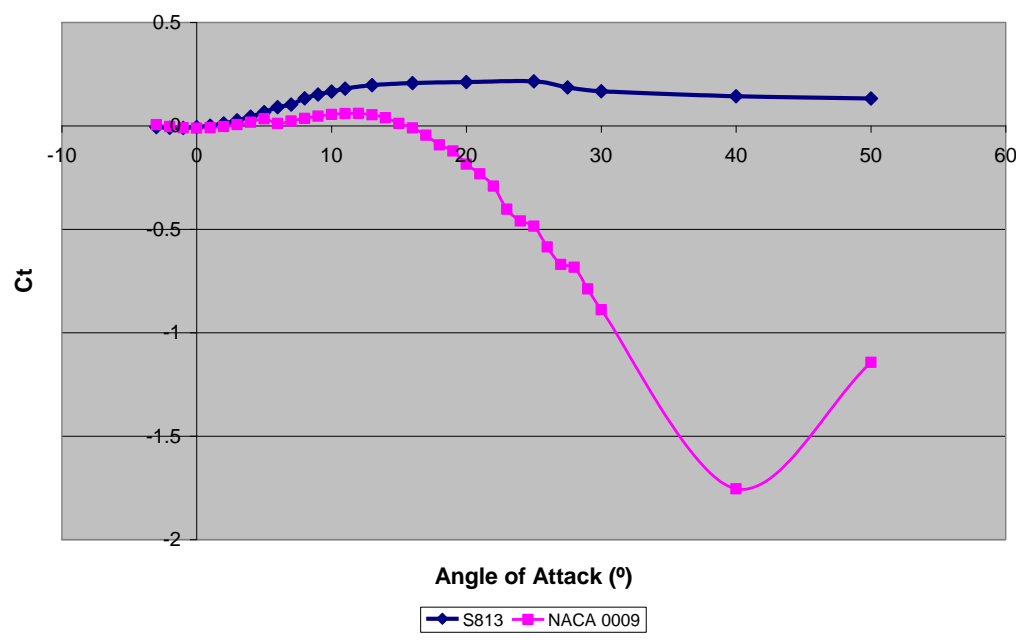

Figure 9: Comparison of the coefficients of tangential force in a blade element of a Darrieus turbine, for a symmetrical and other asymmetric airfoil.

\section{Test In Wind Tunnel}

A small prototype turbine Darrieus-H in order to test the auto start was built. It consists of four rectangular blades $50 \mathrm{~cm}$ span and $5 \mathrm{~cm}$ chord untwisted, mounted on two circular plates $34 \mathrm{~cm}$ in diameter, with a solidity of 0.6.The tests are performed in the wind tunnel No. 2 of the Faculty of Engineering UNComahue, being the test section of $0.90 \times 0.90 \mathrm{~cm}$. This tunnel can function as aerodynamic or atmospheric boundary layer, depending on how one prepare it. For these tests the wind profile was uniform, as the rotor diameter is small and not influenced by the profile of the atmospheric boundary layer, but the turbulence intensity was $15 \%$, modelling an urban environment. 


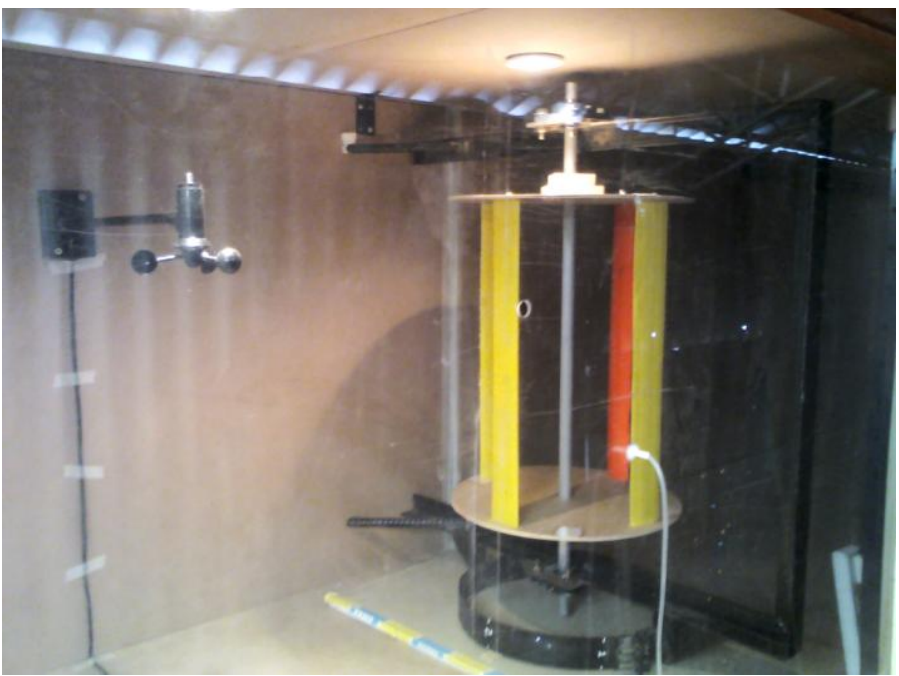

Figure 10: Model Darrieus turbine-H tested in the wind tunnel No. 2 of the FI-UNCo.

The torque is measured by means of a lever arm, by friction on the main shaft, the rotation speed with a digital meter r.p.m., and wind speed with an anemometer automatic weather station Davis Monitor II.

\section{Results Obtained}

In the test, the angle of attack of the blades is varied, taking as reference zero, the tangent to the path describing the aerodynamic centre of the airfoil ( $30 \%$ chord). Wind speed in the tunnel between 3 and $5 \mathrm{~m} / \mathrm{s}$ are varied, simulating the minimum speed for a start. The results are shown in Figure 11, where a wind of $3.6 \mathrm{~m} / \mathrm{s}$ achieved only to $9 \mathrm{rpm}$ rotate with an angle of attack of $10^{\circ}$. With a wind of $4 \mathrm{~m} / \mathrm{s}$, starts and rotates about 20 $\mathrm{rpm}$ for angles of attack between $5^{\circ}$ and $15^{\circ}$. Finally a wind of $5 \mathrm{~m} / \mathrm{s}$, there auto start between $5^{\circ}$ and $20^{\circ}$ angle of attack, the largest to $5^{\circ}$ with $51 \mathrm{rpm}$. The power developed Watt was 1.20 with a $0.1 \mathrm{Cp}$ coincident with results obtained by Qing'an Li et al [14] with a Darrieus H-5 blades and solidity of 0.60 .

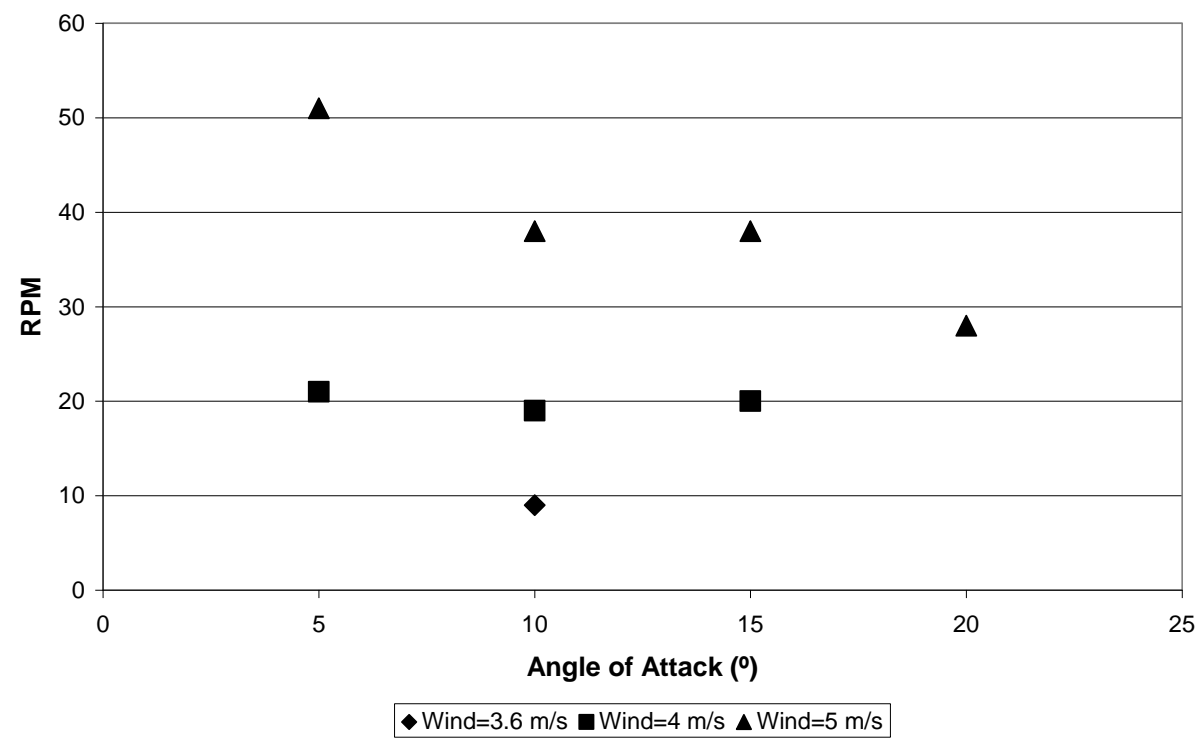

Figure 11: test results, the rpm at which the auto start Darrieus-H was achieved without other assistance, depending on the angle of attack of the blades (built with an asymmetrical airfoil) are indicated.

\section{Conclusion}

The auto start the Darrieus turbine was a problem in the past decades, as symmetrical NACA airfoils were used for high Reynolds numbers. The further development of wind turbine airfoils, determined using profiles of low Reynolds numbers. Power control was also enhanced by the entry of the blades stall, developing for these special airfoils. This is the case airfoil S813, which has a prolonged lift at high angles of attack.In applying the aerodynamic parameters of this profile, the tangents force (through the coefficient of tangential force $\mathrm{Ct}$, equation 8) that occurs in a blade element, the calculations show that there is for high angles of attack 
positive values of $\mathrm{Ct}$, which generate a torque in the direction of rotation of the turbine (figure 9).To check the properties of that airfoil, a blade element of it was constructed and tested in the wind tunnel keep checking the qualities of lift at high angles of attack.Finally a small turbine Darrieus-H was built for wind tunnel tests in order to determine the best angle of the blades, which allow start at the slowest speed possible. The tests confirm that the auto start is possible with this airfoil, from wind speeds of $3.6 \mathrm{~m} / \mathrm{s}$.

\section{Acknowledgements}

This work is made into the research Project Wind Engineering 04/I185 of the National University of Comahue.

\section{References}

[1]. Darrieus G.J.M.; “Turbine Having its rotating shaft transverse to the flow of the current”. US Patent No.1835081; 1931.

[2]. Herbert J. Sutherland, Dale E. Berg, and Thomas D. Ashwill; "A Retrospective of VAWT Technology"; SANDIA REPORT, SAND2012-0304, Unlimited Release, Printed in Albuquerque, California USA, January 2012.

[3]. Francesco Balduzzi, Alessandro Bianchini, Ennio Antonio Carnevale, Lorenzo Ferrari, Sandro Magnani; "Feasibility analysis of a Darrieus vertical-axis wind turbine installation in the rooftop of a building"; Applied Energy 97 (2012) 921-929.

[4]. M. El-Samanoudy, A.A.E. Ghorab, Sh.Z. Youssef; Effect of some design parameters on the performance of a Giromill vertical axis wind turbine; Ain Shams Engineering Journal (2010) 1, 85-95.

[5]. South, P. and Rangi, RS.; "Preliminary Tests of a High Speed Vertical Axis Windmill Model", National Research Council of Canada, LTR-LA-74, March 1971.

[6]. South, P. and Rangi, RS.; "A Wind Tunnel Investigation of a 14 Ft. Diameter Vertical Axis Windmill”, National Research Council of Canada, LTR-LA- 105,

[7]. Kirke BK; "Evaluation of self-starting vertical axis wind turbines for stand-alone applications". PhD thesis, Griffith University, Australia, 1998

[8]. Hoerner S.F., "Fluid - Dynamics Lift," Published by the Author (1975).

[9]. Eppler, R., and D.M. Somers, "A Computer Program for the Design and Analysis of Low Speed Airfoils", Technical Memorandum 80210, NASA, Aug. 1980

[10]. McGhee, R. J., and W. D. Beasley, "Low - Speed Aerodynamics Characteristics of a 17 - Percent - Thick Section Designed for General Aviation Applications", TN D-7428 NASA, Dec. 1973.

[11]. Eppler, Richard "Airfoil Design and Data". Springer - Verlag , Berlin, 1990

[12]. C.A. Carroll, A.P. Broeren, P. Giguere, A. Gopalarathnam, C.A. Lyon and M.S. Selig. Low Reynolds Number Airfoil Design and Wind Tunnel Testing, UIUC, 1990 - 2000.

[13]. Somers D.S.; Effect of Flap Deflection on Section Characteristics of S813 Airfoil; NREL/SR-500-36335; January 2005.

[14]. Qing'an Li, TakaoMaeda, YasunariKamada, JunsukeMurata, KazumaFurukawa, MasayukiYamamoto; Measurementofthe flow field aroundstraight-bladedverticalaxis wind turbine; J.WindEng.Ind.Aerodyn.151(2016)70-78. 